\title{
GRANDES PROJETOS AGRO-MINERO-EXPORTADORES NA INSERÇÃO DA SILVICULTURA DO EUCALIPTO NA AMAZÔNIA MARANHENSE
}

\author{
Allison Bezerra Oliveira \\ Universidade Estadual da Região Tocantina do Maranhão, Imperatriz, MA, Brasil \\ allisonbzr@gmail.com \\ Diego Armando de Sousa Paz \\ Universidade Estadual da Região Tocantina do Maranhão, Imperatriz, MA, Brasil \\ d.armando146@hotmail.com \\ Amanda Miranda Pereira \\ Universidade Estadual da Região Tocantina do Maranhão, Imperatriz, MA, Brasil \\ amandamirandh@gmail.com
}

\begin{abstract}
RESUMO
A expansão da cultura do eucalipto no Maranhão, especificamente na porção amazônica, resulta de processos iniciados nos anos 1980 e representa um padrão de reprodução de capital fincado na economia de fronteira. O objetivo deste trabalho é entender como se deu o processo de inserção e avanço da fronteira agrícola da silvicultura do eucalipto na região amazônica do estado. Para isso, resgata os principais acontecimentos que permearam esse processo desde os anos 1980 até os dias atuais. Apresenta fotografias e mapas referentes às áreas de plantio de eucalipto, dentro do recorte da pesquisa; e gráficos sobre a produção de carvão vegetal e madeira de eucalipto, extensão de áreas plantadas e exportações estaduais de commodities, incluindo pasta de celulose. Os dados coletados advêm do trabalho de campo e de bases secundárias, como Indústria Brasileira de Árvores, Instituto Brasileiro de Geografia e Estatística e Empresa Maranhense de Administração Portuária. Os resultados sugerem que a fronteira da silvicultura do eucalipto não é fruto apenas de movimentos próprios, mas legado de grandes projetos agro-minero-exportadores implantados na região desde os anos 1980 , os quais viabilizaram a constituição da base plantada que agora se consolida com o Grande Projeto Suzano Papel e Celulose.
\end{abstract}

Palavras-chave: Fronteira agrícola. Agroexportação. Monocultura do eucalipto. Maranhão.

\section{GREAT AGRO-MINERO-EXPORT PROJECTS IN THE INSERT OF EUCALYPTUS FORESTRY IN THE AMAZON MARANHENSE}

\begin{abstract}
The expansion of the eucalyptus culture in the state of Maranhão, specialy in the Amazon portion, is the result of process that was initiated in the years 1980 and shows a pattern to reproduce the capital based in border economy. The goal of this article is to understand how the insertion and increase process of the farming of the forestry of eucalyptus in the Amazon region of the state. To achieve this goal, we revive the main events of this process since 1980 until the present days, presenting pictures and maps about the eucalyptus planting area and charts about the production of charcoal and eucalyptus wood, extension of the plantation area and state export of commodities, including cellulose pulp. The data collected are based in field research and secondary sources, as the Brazilian industry of forestry, Geography and statistics Brazilian institute, and Maranhense company of harbor administration. The outcome suggests that the eucalyptus forestry borders are not only selfmovements but legacy of big agro-miner-export projects deployed in the region since the years 1980, which made possible the constitution of the cultivation which now is consolidated as the big project of paper and cellulose Suzano.
\end{abstract}

Keywords: Agricultural frontier. Agro export. Eucalyptus monoculture. Maranhão.

\section{INTRODUÇÃO}

A fronteira agrícola representa, historicamente, o padrão de reprodução econômica incorporado pelo Brasil em suas políticas macroeconômicas, sobretudo aquelas oriundas do final do século XX. Assim, 
considerando seu potencial natural e sua capacidade de terras cultiváveis, o país optou por especializar-se na agro-minero-exportação, assumindo seu papel na divisão internacional do trabalho como produtor de commodities e produtos de baixo valor agregado. Esse padrão simboliza as clássicas fragilidades na estrutura produtiva nacional, que, ao longo dos anos, tomou como principal referência de desenvolvimento econômico o modelo colonial baseado na pilhagem de recursos.

Para Becker (1999, 2005), essas características estão vinculadas ao fato de a ocupação do atual território brasileiro ter ocorrido no contexto da expansão marítima europeia, o que levou o país a se constituir em uma das mais antigas periferias do mundo capitalista. Forjado, desse modo, no paradigma sociedade-natureza, denominado "economia de fronteira", segundo o qual o progresso está ligado ao crescimento econômico e à prosperidade, julgados como oriundos de uma fonte infinita, qual seja a exploração de recursos naturais considerados ilimitados.

Desta forma, a fronteira agrícola pode ser considerada como a incorporação de novas terras à produção agrícola, aumentando assim o avanço sobre áreas naturais ou consideradas subutilizadas (terras quilombolas e do campesinato). Essas áreas são vistas como "desocupadas" ou "vazios econômicos" a serem integrados, contribuindo para a ampliação produtiva no âmbito agrícola, mineral ou florestal.

Na segunda metade do século XX intensificou-se movimentos de expansão da fronteira agrícola para diversas regiões do país. A Amazônia Legal brasileira, em específico, passou por profundas transformações em suas estratégias de desenvolvimento, sobretudo a partir da década de 1960. Isso porque em 1966 a Superintendência do Plano de Valorização Econômica da Amazônia (SPVEA) foi transformada em Superintendência do Desenvolvimento da Amazônia (SUDAM).

Algumas dessas estratégias podem ser percebidas nos processos de integração nacional adotados pelo Estado brasileiro que, por meio da construção de infraestruturas de energia (como a usina de Tucuruí) e de transportes (como a Rodovia Belém-Brasília), além da atração de grandes empreendimentos industriais (de ordem mineral, agrícola e florestal), modificaram a estrutura produtiva, alterando estruturas urbano-regionais e dinâmicas territoriais em toda uma região.

Cabe destacar os movimentos de introdução do eucalipto na fronteira agrícola da Amazônia maranhense, iniciados na década de 1980. Hoje, o estado conta com mais de 225 mil hectares destinados à cultura. Desta forma, este trabalho objetiva entender como se deu o processo de inserção e avanço da fronteira agrícola da silvicultura do eucalipto na região amazônica do Maranhão. Como hipótese, acredita-se que tal fronteira não resulte apenas de movimentos próprios, mas de subprodutos das implantações de grandes projetos agro-minero-exportadores que, a partir dos anos 1980, permitiram que se constituísse a base plantada que agora se consolida com o Grande Projeto Suzano Papel e Celulose.

Metodologicamente, fez-se um resgate dos principais acontecimentos que permearam a inserção da silvicultura do eucalipto no Maranhão, tendo como recorte espacial a porção amazônica do estado; como recorte temporal, analisou-se o período de 1980 até os dias de hoje, dividindo-o em décadas. A discussão teórico-conceitual sobre a fronteira agrícola da Amazônia apoiou-se em Becker (1985, 1999, 2005, 2007) e Sicsú e Lima (2000); além de apoiar-se nos estudos de Oliveira (2019) para discutir a expansão da silvicultura de eucalipto na região.

Além do referencial teórico, foram utilizadas imagens de acervo fotográfico e produção cartográfica referente às áreas destinadas ao plantio de eucalipto, dentro do recorte da pesquisa. Em paralelo, foram construídos gráficos a partir de dados sobre: a produção de carvão vegetal e madeira de eucalipto; a extensão das áreas plantadas nos municípios maranhenses; e as exportações estaduais de commodities, incluindo a pasta de celulose. A coleta de dados foi feita nos trabalhos de campo e em bases de dados secundárias, como a Indústria Brasileira de Árvores, o Instituto Brasileiro de Geografia e Estatística e a Empresa Maranhense de Administração Portuária.

Além desta introdução, das considerações finais e referências, o trabalho divide-se em mais cinco seções. Primeiro discute-se o conceito e o ideário de fronteira agrícola; em seguida, apresenta-se o contexto de criação da Amazônia Legal. Na sequência, são apresentados os primeiros movimentos de inserção do eucalipto no Maranhão, com o Projeto Grande Carajás. A seção seguinte aborda a criação da Indústria de Celulose do Maranhão (Celmar) e a tentativa de produzir commodities agroflorestais; por último, discute-se a consolidação da silvicultura do eucalipto com o Projeto Suzano Papel e Celulose, a partir de 2008. 


\section{O IDEÁRIO DA ECONOMIA DE FRONTEIRA BRASILEIRA}

A fronteira agrícola se revela na própria gênese da formação territorial brasileira, nos diversos ciclos econômicos, processos de migração e ocupação do país. A exemplo das frentes de penetração que buscavam pedras preciosas; expansão pecuária no vale do Rio São Francisco; atividades portuárias, no litoral; expedições em busca das "drogas do sertão"; expansão cafeeira e mesmo o ciclo da borracha, na região Norte. Todos se mostraram como fluxos de frentes agrícolas pioneiras.

Fronteira agrícola é o avanço da produção capitalista sobre a natureza (áreas preservadas ou em transição; terras cultiváveis, indígenas ou de agricultura familiar). Esses espaços naturais ou pouco povoados são vistos a partir de seu potencial produtivo (primordialmente vinculado ao setor primário) e transformados por diversos agentes públicos e/ou privados com vistas à intensificação da demanda por produção agrícola e por produtos da pecuária para os mercados interno e externo. Há, desta forma, um aumento da capacidade produtiva de gêneros alimentícios a partir da ampliação de áreas destinadas à produção e da expropriação de recursos naturais.

A fronteira agrícola baseia-se no modelo de economia de fronteira, no qual "o crescimento econômico é visto como linear e infinito, e baseado na contínua incorporação de terra e de recursos naturais, que são também percebidos como infinitos" (BECKER, 2005, p. 71), o que resulta em intensas transformações dos ambientes naturais, culturais e políticos com vistas ao aumento da produtividade e reprodução econômica das atividades em novas áreas agregadas. Desse modo, o povoamento das regiões e os processos econômicos de desenvolvimento fundamentaram-se no paradigma da relação sociedade-natureza, calcados nessa economia de fronteira.

Para Becker (1985), a fronteira agrícola é um espaço não estruturado plenamente, cuja definição considera reservas de recursos, sobretudo naturais, e espaço para manobra política e ideológica, destacando o viés desenvolvimentista que prevê a expansão do capital em áreas naturais ou de culturas preexistentes, gerando conflitos pelo uso e posse da terra e dos recursos naturais.

Nessa mesma perspectiva, Sicsú e Lima (2000) entendem a fronteira agrícola como regiões relativamente desocupadas e economicamente pouco exploradas, que oferecem amplas possibilidades de ocupação produtiva. Seriam, assim, espaços ou "vazios econômicos" ricos em recursos naturais (solo, recursos minerais e florestais); não devidamente integrados à base econômica tradicional, em razão de fatores como localização, condições naturais e deficiências de infraestrutura; e que apresentam uma ocupação incipiente ou abaixo de suas potencialidades.

Ainda segundo os autores, a fronteira agrícola envolveria, basicamente, terras devolutas, passíveis de apropriação por camponeses ou pioneiros. Mais recentemente, esse caráter aberto e extensivo da fronteira tem sido substituído por novas características, atribuídas, principalmente, pela dimensão dos capitais envolvidos. Entre elas estão a heterogeneidade das atividades desenvolvidas nas fronteiras e a intensa participação do Estado no planejamento e nos investimentos em infraestruturas.

Desse contexto, podemos compreender que até a primeira metade do século XX havia uma predominância de fronteiras agrícolas constituídas por movimentos pioneiros de trabalhadores, pequenos produtores e camponeses que promoveram fluxos migratórios, constituíram cidades e estabeleceram atividades de base agrícola e pecuária em diversas regiões do país. Essas frentes, em sua maioria, eram voltadas para a agricultura de subsistência, pequena e média produção comercial, frentes especulativas e pecuária.

$\mathrm{Na}$ segunda metade do século $\mathrm{XX}$, esse movimento perdeu força para outro movimento, fruto da intensificação da abertura dos mercados de commodities. Com forte ação estatal e capital privado, o que se observa a partir da década de 1970 é o redirecionamento de frentes de fronteira com vistas a atender ao capital hegemônico através de grandes projetos agroexportadores em diferentes regiões do país. Tais iniciativas resultam da ação do grande capital privado estrangeiro e nacional, oriundo sobretudo das regiões Sudeste e Sul.

Por meio de incentivos fiscais, venda ou cessão de terras da União e obras de infraestrutura, as ações do Estado têm reestruturado as fronteiras agrícolas, transformando-as em "frentes capitalistas" (SICSÚ; LIMA, 2000). Como resultado, amplia-se a lucratividade do capital investido, favorecendo a acumulação e a penetração das relações capitalistas no processo produtivo que se desenvolve nas regiões, expandindo a oferta de bens primários e ampliando a capacidade produtiva para exportação.

A intensificação da penetração capitalista nas regiões de fronteira no Brasil, aliada ao padrão de reprodução baseado na especialização produtiva para a exportação de produtos primários, resultou, sobretudo a partir da década de 1970, na inserção de grandes projetos na economia de fronteira brasileira. Fortemente amparados em infraestruturas de transportes, energia, incentivos fiscais, uso e 
ocupação da terra, esses projetos, em sua maioria, eram vinculados à produção de biocombustível, exploração florestal e mineral.

A criação dos grandes projetos é resultado de mudanças nas estratégias de desenvolvimento estabelecidas nas diversas regiões do país, associadas às políticas de avanço da fronteira agrícola. Com a Amazônia Legal não foi diferente, em especial com a sua porção maranhense. Tais projetos aceleraram as transformações socioeconômicas regionais, e, em paralelo, alteraram a paisagem natural dessas regiões a partir da predominância de culturas vegetais exóticas.

\section{A AMAZÔNIA LEGAL MARANHENSE}

Para compreender o processo de formação socioeconômica do Maranhão, é necessário entender que ele ocorre a partir de modelos históricos de ocupação territorial baseados em ciclos econômicos e expansão das fronteiras regionais. Nesse sentido, a inserção desse território na Amazônia Legal (Figura 1) é fundamental para se entender os contornos resultantes de movimentos históricos que repercutem até os dias de hoje. Deve-se, portanto, considerar a especificidade geográfica do estado do Maranhão na composição da Amazônia Legal.

Figura 1 - Brasil: Delimitação da área da Amazônia Legal, 2020.

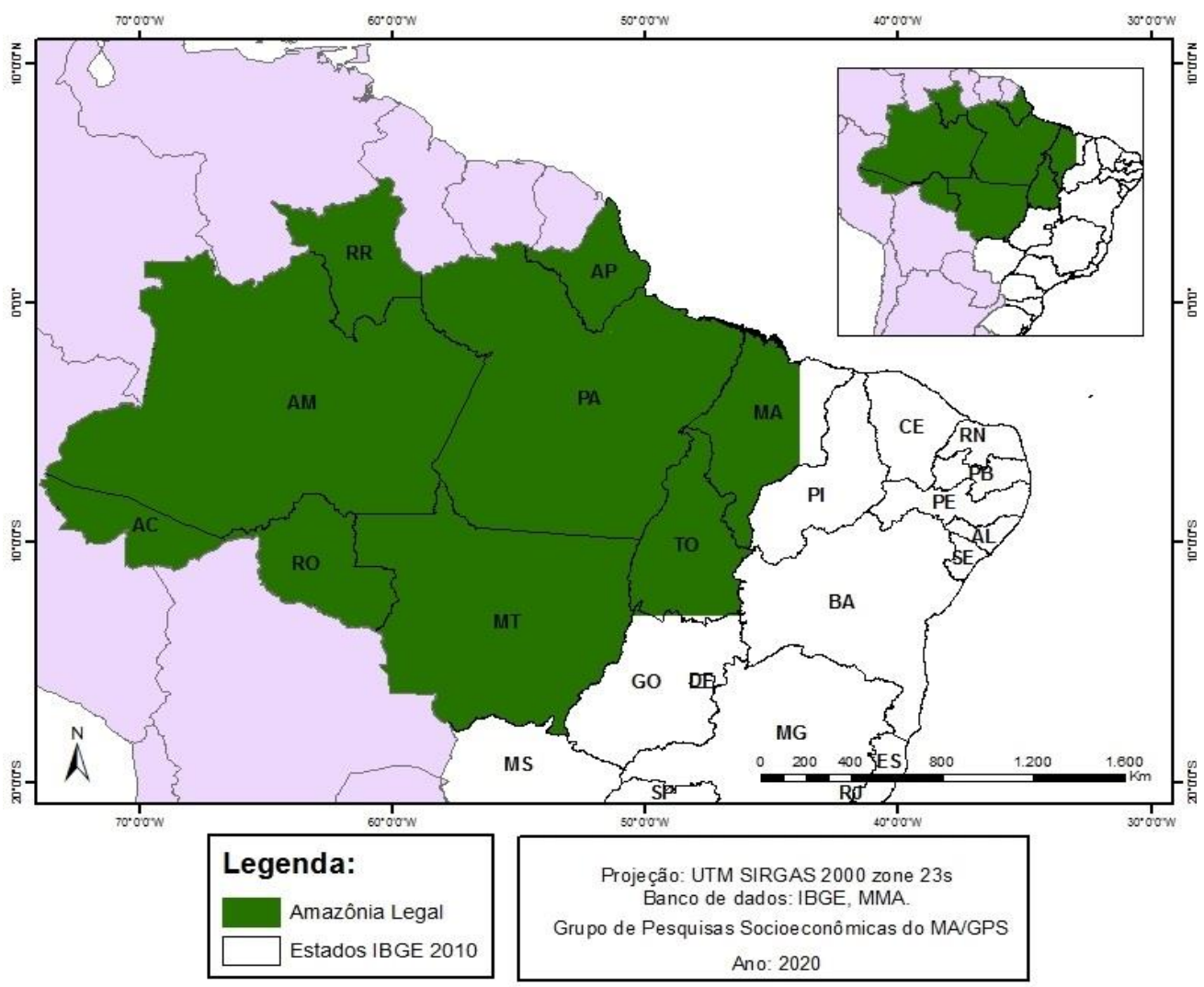

Organização: Os autores (2020).

Como apresentado na Figura 1, nove estados fazem parte da Amazônia Legal, quais sejam: Acre, Amapá, Amazonas, Mato Grosso, Pará, Rondônia, Roraima, Tocantins e uma parte do Maranhão. Embora as características naturais, com predomínio do bioma amazônico, sejam o principal critério de incorporação à Amazônia Legal, são consideradas também as questões políticas e os interesses públicos e privados na delimitação dessa área que compreende um conceito político-administrativo.

Ocupando uma posição de transição entre três macrorregiões brasileiras (Norte, Nordeste e Centro-Oeste), a porção amazônica maranhense abrange uma área equivalente a $80 \%$ da superfície territorial do estado $\left(264 \mathrm{mil} \mathrm{km}^{2}\right)$, a oeste do meridiano $44^{\circ} \mathrm{W}$, compreendendo 181 dos seus 217 municípios, distribuídos em cinco mesorregiões e 21 microrregiões. (MESQUITA et al., 2015, p. 227). 
Aqui, consideramos a constituição da Amazônia Legal frente à construção de uma fronteira agrícola fruto de um processo de extrema mercantilização da natureza, e, como afirma Becker (2007), influenciada pela ação estatal dos governos de Getúlio Vargas e Juscelino Kubitschek, com projetos como a "Marcha para o Oeste", iniciado em 1938, e rodovias de penetração nacional.

Para fins de administração, instituíram-se os limites da Amazônia Legal definindo as linhas básicas do desenvolvimento regional. Foi criada também a Superintendência do Plano de Valorização Econômica da Amazônia (SPVEA), com base em discursos governamentais que se propunham a diminuir as desigualdades regionais, assegurar a ocupação da Amazônia, valorizar o território amazônico e promover o desenvolvimento da região e sua integração ao restante do país.

Ao fim da década de 1950, os investimentos estatais do governo JK provocaram a demanda crescente por matérias-primas e alimentos, possibilitando a rápida integração da economia do Maranhão ao mercado brasileiro por meio da divisão nacional do trabalho. Em 1959, a Lei no 3.692 instituiu a Superintendência de Desenvolvimento do Nordeste (SUDENE), cujos objetivos eram planejar a economia, buscar o crescimento econômico e reduzir as disparidades inter-regionais que persistiam apesar do crescente processo de industrialização.

Contudo, foi somente entre 1966 e 1985 que se iniciou o planejamento efetivo da região, com o Estado tomando a frente de um novo e ordenado ciclo de economia de fronteira, num projeto geopolítico para a modernização acelerada da sociedade e do território nacional. Nesse projeto, a ocupação da Amazônia foi prioridade por várias razões, dentre as quais solucionar tensões sociais internas geradas pela expulsão de pequenos produtores de diversas áreas do país e utilizar a área como produtora de matérias-primas para o país que então se industrializava (BECKER, 2007).

Com o objetivo de agilizar o processo de ocupação da região, o governo extinguiu a SPVEA e criou a SUDAM, através da Lei no 5.173, de 27 de outubro de 1966 (BRASIL, 1966); assim, o conceito de Amazônia Legal foi reinventado para fins de planejamento. A SUDAM atuou principalmente na atração de investimentos por meio do Fundo de Investimentos da Amazônia (FINAM) e dos incentivos fiscais. Na mesma época, a Amazônia Legal foi dividida em Amazônia Ocidental, composta pelos estados do Amazonas, Acre, Rondônia e Roraima; e Amazônia Oriental, constituída pelo Tocantins, Pará, Amapá e áreas amazônicas do Mato Grosso e Maranhão.

\section{GRANDE CARAJÁS, ESPECIALIZAÇÃO MINERO-EXPORTADORA E A INTRODUÇÃO DA SILVICULTURA DO EUCALIPTO NO MARANHÃO NA DÉCADA DE 1980}

Espécie exótica ao bioma brasileiro, o eucalipto é uma árvore oriunda da Oceania e que se acredita ter chegado ao Brasil em meados do século XIX, com o objetivo de suprir as necessidades de lenha, postes e dormentes das estradas de ferro. Esse período coincide com o início da criação das primeiras indústrias de papel ${ }^{1}$ do país. A instalação dessas indústrias começou a ocorrer em 1830, mas seu desenvolvimento torna-se mais evidente somente em 1920, graças aos incentivos fiscais do governo para a constituição de base plantada de eucalipto vindo da Austrália, para o melhoramento genético e importação de bens de capital para a produção (SUZIGAN, 2000).

Foram criados, neste momento (entre 1920 e 1960), incentivos fiscais para a atividade de reflorestamento de eucalipto, gerando um aumento da área de plantio de 500 mil para 3 milhões de hectares, iniciando, assim, a silvicultura propriamente dita dessa espécie no país. $\mathrm{Na}$ ocasião, o plantio concentrava-se na região centro-sul (em específico nos estados de Minas Gerais, São Paulo, Paraná, Santa Catarina, Rio Grande do Sul e Mato Grosso do Sul), realidade que se alterou somente na segunda metade do século $X X$.

Assim, o reflorestamento em larga escala no Brasil iniciou-se apenas na década de 60 do século passado, quando foi sancionada a Lei № 5.106 , de 1966, com os incentivos fiscais recolhidos ao Fundo de Investimento Setorial - FISET Reflorestamento e aplicados mediante a aprovação de projetos apresentados ao então Instituto Brasileiro de Desenvolvimento Florestal - IBDF. (VIANA, 2004, p. 4).

\footnotetext{
${ }^{1}$ Nessa época, a cadeia produtiva limitava-se à cadeia do papel. A de celulose ainda não havia sido incorporada, pois, até então, a pasta de celulose era importada dos Estados Unidos. 
Para essa expansão, concorreram outros programas, tais como: Programa de Reflorestamento de Pequenos e Médios Imóveis Rurais (REPEMIR); Programa Nacional de Papel e Celulose; Programa de Siderurgia a Carvão Vegetal; e Programa de Substituição Energética; além de iniciativas privadas sem incentivo do poder público (ANTONANGELO; BACHA, 1998).

Governos como o de Getúlio Vargas (1930-1945) e Juscelino Kubitschek (1956-1961) potencializaram os processos de industrialização e de expansão das infraestruturas de transportes com vistas à agroexportação. Mesmo essa sendo uma característica histórica da economia brasileira, foi no Regime Militar (1964-1985) que a especialização na produção de matéria-prima recebeu um imenso aporte através dos grandes projetos, principalmente no fim da década de 1970 e início da de 1980.

Para o vetor da Amazônia Oriental, destacam-se os projetos de ordem de três principais eixos: a) mínero-metalúrgicos, b) infraestrutura e c) agroflorestal. No primeiro eixo, estava o Programa Grande Carajás, projeto de investimento da então estatal Companhia Vale do Rio Doce (CVRD), além da construção da Usina Hidroelétrica de Tucuruí (UHT), a Mineração Rio do Norte (MRN), a Albras e a Alunorte, todos na Amazônia Legal paraense.

Os grandes projetos teriam resultado da presença do capital transnacional, apoiado pelo governo federal, totalizando 33 projetos de investimento. Em 1983, já estava concluída a infraestrutura básica do Complexo Grande Carajás: as instalações industriais, os equipamentos de lavra, beneficiamento e manuseio do minério, além das usinas de britagem (COELHO, 2015).

No âmbito da infraestrutura, tais projetos resultaram na construção da Estrada de Ferro Carajás (Figura 2), também conhecida como Ferrovia Carajás-Itaqui, inaugurada em 1985. Uma ferrovia de 892 km (destes, 695 km no Maranhão e 197 km no Pará), que percorre, atualmente, 4 municípios no estado do Pará e 23 municípios no Maranhão. Atualmente o trem da EFC é composto por 330 vagões e tem 3,5 quilômetros de extensão. Resultaram, ainda, na implantação de dois portos especializados, próximos ao Itaqui; na ampliação da rede de energia elétrica; e na construção dos primeiros 100 km da Ferrovia Norte-Sul (entre Açailândia e Imperatriz), entregues em 1989.

Figura 2 - Maranhão e Pará: Principais municípios por onde passa a Estrada de Ferro Carajás.

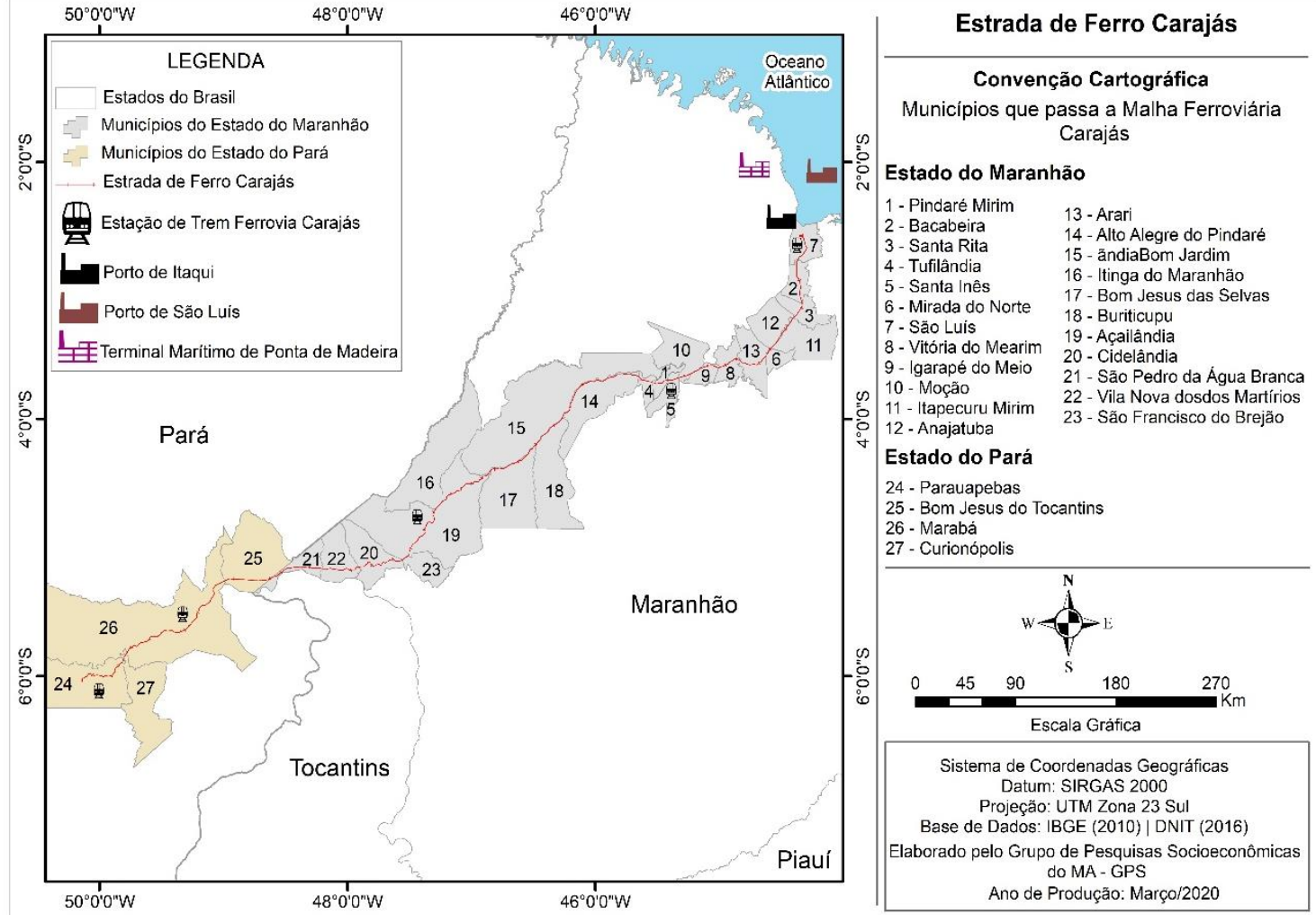

Organização: Os autores (2020) 
No contexto de um ideário desenvolvimentista e associado à expansão da Estrada de Ferro Carajás e do então complexo portuário Itaqui-Madeira, o Projeto Grande Carajás levou o Maranhão a uma especialização minero-exportadora através de projetos como: o Consórcio de Alumínio do Maranhão (ALUMAR) e a Alcoa, criados em 1981, em São Luís. Além destes, destaca-se, ainda, o complexo de produção de ferro-gusa, formado por sete indústrias. Destas, cinco estão localizadas no município de Açailândia (Ferro-gusa do Maranhão, Gusa Nordeste, Siderúrgica do Maranhão - SIMASA, Companhia Siderúrgica Vale do Pindaré e Viena Siderúrgica do Maranhão); uma em Bacabeira (Margusa); e uma em Pindaré-Mirim (Cosima).

As indústrias dependem do carvão vegetal, que é a principal fonte de energia para as caldeiras de produção do ferro-gusa. Para produzir uma tonelada de ferro-gusa são necessários, em média, 875 $\mathrm{kg}$ de carvão vegetal, que, por sua vez, demandam cerca de $2.600 \mathrm{~kg}$ de madeira seca, gerando um desmatamento de pelo menos $600 \mathrm{~m}^{2}$ de matas primárias para cada tonelada (MONTEIRO, 2004).

Foi, então, devido à demanda de carvão para as atividades produtivas minero-exportadoras que a monocultura de eucalipto foi inserida, em larga escala, no Maranhão, na década de 1980, com ênfase para os projetos iniciais nos municípios de Imperatriz e Açailândia. O "boom" das commodities minerais (minério de ferro, ferro-gusa, bauxita, alumínio e cobre), nessa mesma década, incentivado pelo aumento das importações dos mercados chinês e estadunidense, influenciou o arrendamento e a concentração de terras em nome de siderúrgicas para o plantio de eucalipto que, em pouco mais de uma década, iria se espalhar por todo o estado, não apenas na sua porção amazônica.

A velocidade da expansão da fronteira agrícola do eucalipto coincide com o desmatamento de domínios nativos (amazônico e do cerrado) para a produção de carvão, madeira para a construção civil e criação de pastagens. Há nesse contexto uma estrutura histórica interligada: onde as atividades madeireiras retiraram madeira de lei, consequentemente as siderúrgicas derrubaram as madeiras finas, a "capoeira", e as áreas onde não havia mais mata nativa foram transformadas em pasto e fazendas de eucalipto.

\section{PROJETO CELMAR E A TENTATIVA DE PRODUÇÃO DE COMMODITIES AGROFLORESTAIS NAS DÉCADAS DE 1990 E 2000}

A Indústria de Celulose do Maranhão (CELMAR) surgiu em 1992 em consonância com as transformações ocorridas no estado na década anterior. Ela surge como um subproduto dos processos de reestruturação e especialização produtiva que a precederam, destacando três variáveis, a saber: a) a CELMAR era um projeto da CVRD, a mesma controladora do Projeto Carajás; b) sua criação fincava-se na aquisição de base plantada de eucalipto na década de 1980; e c) ela se apropriava de um ideário ambiental, com a proximidade da realização da ECO-92, para propagar o discurso de desenvolvimento sustentável e de benefícios que esse tipo de empreendimento poderia proporcionar à Região Tocantina do Maranhão.

A Celmar foi o primeiro projeto do Programa Polos Florestais, que foi um programa lançado em 1990 pelo governo brasileiro com a intenção de manter e recuperar a vegetação da Amazônia Oriental. O programa foi concebido pela CVRD para ser executado também por ela, que, por ter participação em várias siderúrgicas da região, era proprietária de extensas áreas de monocultura de eucalipto na região de influência da Estrada de Ferro Carajás (EFC). O plano previa a implantação de, no mínimo, dez fábricas com capacidade para a produção de, pelo menos, 420 mil toneladas de pasta de celulose ao ano (MATIAS, 1994).

Esse programa resultou também de transformações mais amplas de cunho global decorrentes da crise pós-fordista, que acelerou os processos de desindustrialização da indústria de celulose nos países do Hemisfério Norte, que optaram por transferir os estágios iniciais da cadeia produtiva de papel e celulose - de menor valor agregado e mais onerosos do ponto de vista socioambiental - para os países periféricos, como o Brasil, seguindo os modelos de desenvolvimento desigual e combinado do mundo capitalista (OLIVEIRA, 2019).

Às vésperas da ECO-92 e ancorada no argumento básico de reflorestamento de áreas degradadas e conciliação de desenvolvimento sustentável e geração de emprego e renda, a CELMAR se utilizou desse contexto para viabilizar a captação de recursos a fundo perdido para a implantação, na cidade de Imperatriz, do megaconsórcio formado pelo grupo Risipar, com 55\% do capital; CVRD, com 30\%; e a empresa japonesa Nissho Iwai Corporation, com $15 \%$. 
A construção da indústria foi prevista para ter início no ano de 1996, com conclusão em 1999. A estimativa era de que ela atingiria $100 \%$ de sua capacidade produtiva, de 420 mil toneladas anuais, até o terceiro ano de funcionamento, contando inicialmente com uma área 80 mil hectares plantados, sendo prevista a compra de mais 180 mil hectares até o ano de 2001.

Em paralelo a essa iniciativa, dentro do Programa Polos Florestais estava também o Projeto Florar, cujo início das operações estava previsto para 1999 em toda a área de influência da Estrada de Ferro Carajás. Participavam desse projeto as empresas consorciadas Aracruz Celulose (com 40\%), CVRD (com 20\%) e uma holding escandinava (com 40\%); sua capacidade de produção era de 500 mil toneladas anuais de fibra curta branqueada, produzidas em uma área de 250 mil hectares (MATIAS, 1994).

Por questões como liberação de capital para início das atividades (orçamento inicial de U\$\$ 960 milhões), o grande projeto de polos florestais na Amazônia Oriental, em especial a CELMAR, não foi instalado na Região Tocantina do Maranhão. Contudo, a preparação para a implementação do projeto já havia estimulado a compra de terras, de modo que, como consequência, houve um aumento da especulação e da concentração de terras para a monocultura do eucalipto. Mediante o fracasso da produção de commodities agroflorestais, a CVRD e as indústrias siderúrgicas concentraram ainda mais a produção de carvão e toras de madeira (Figura 3) para diversos fins.

Figura 3 - Produção de toras de madeira e lenha nos municípios da Amazônia Legal Maranhense (1990-2010).

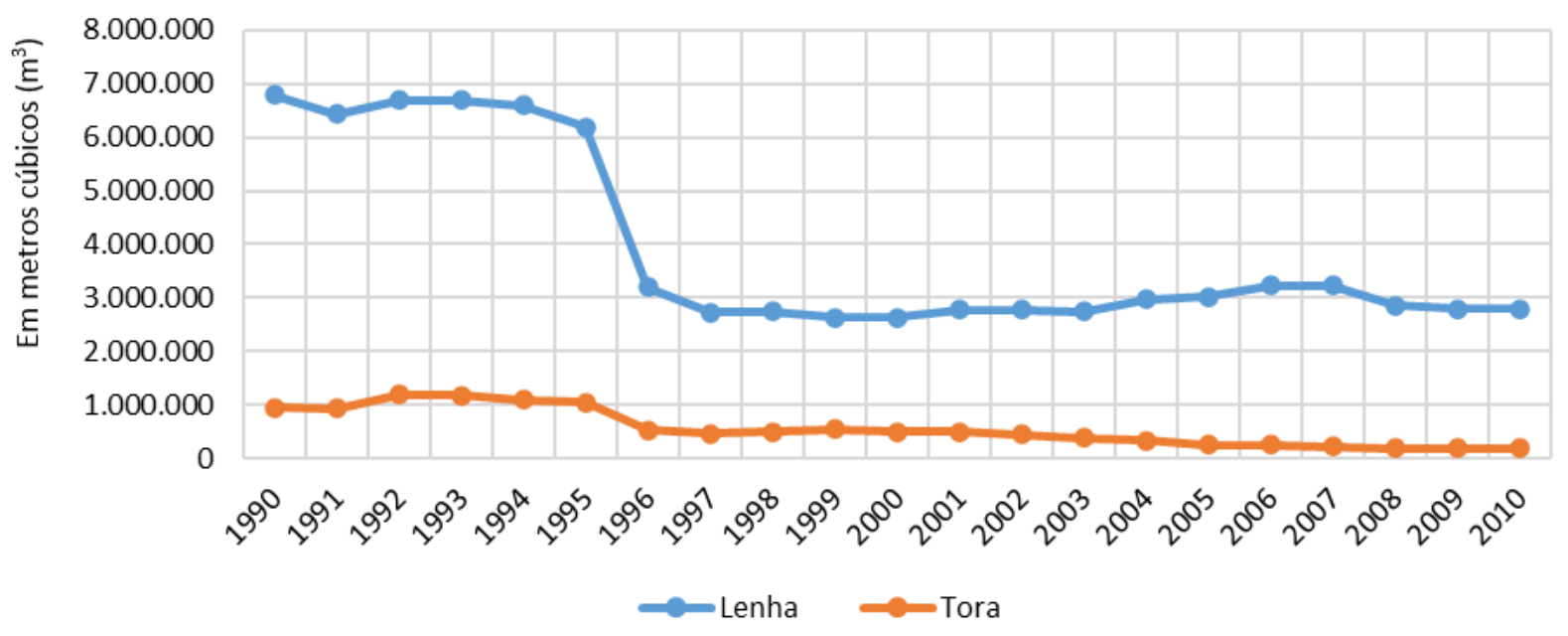

Fonte - IBGE, 2019. Organização: Os autores, 2020.

A Figura 3 apresenta o volume de produção de lenha para o fabrico de carvão vegetal, combustível para as caldeiras das indústrias de ferro-gusa, e de madeira em tora para a construção civil, entre os anos de 1990 e 2010. A produção de toras de madeira foi bem pequena se compararmos com a de lenha para carvão, entretanto, em ambos os casos, o período em que mais se produziu foi a década de 1990. No caso do carvão, isso ocorreu devido ao aquecimento do mercado internacional de ferrogusa; já no da madeira em tora, deu-se pela expansão urbana das cidades da Amazônia Oriental.

A realidade da década de 1990 mudou significativamente nos anos 2000. Houve uma diminuição da produção de ferro-gusa no Maranhão em função da maior competitividade de outros países: a produção que era de $6.787 .783 \mathrm{~m}^{3}$, em 1990, caiu para 2.795.635 $\mathrm{m}^{3}$, em 2010. O mesmo aconteceu com a madeira em tora, que teve uma redução de $954.000 \mathrm{~m}^{3}$, em 1990, para $496.821 \mathrm{~m}^{3}$, em 2000, e $182.173 \mathrm{~m}^{3}$ em 2010. Nos dois casos existe um elemento que redirecionou praticamente todo o eucalipto da região: o projeto Suzano Papel e Celulose.

\section{SUZANO PAPEL E CELULOSE E A CONSOLIDAÇÃO DA FRONTEIRA AGRÍCOLA DO EUCALIPTO NA AMAZÔNIA MARANHENSE}

Três décadas se passaram desde a introdução da monocultura do eucalipto no Maranhão com vistas à produção de ferro-gusa nos complexos industriais desse segmento. As dinâmicas econômicas que 
se reproduziram desde então permitiram a devida inserção dessa cultura na paisagem regional amazônica. A base florestal estabelecida, conjuntamente com outros elementos espaciais (recursos hídricos, terra barata, incentivos fiscais, infraestrutura ferroportuária etc.), permitiram o início das obras do Grande Projeto Suzano Papel e Celulose no ano de 2008. As atividades da indústria foram iniciadas no segundo semestre de 2013.

Esse projeto industrial inaugurou uma nova etapa na fronteira agrícola do eucalipto na Amazônia maranhense, reestruturando os modelos clássicos de reprodução de capital alicerçados nos grandes projetos agro-minero-exportadores. Tais projetos, por sua vez, fazem parte de um contexto mais amplo de investimentos públicos e privados não restritos ao âmbito da produção da celulose, mas ligados a um cenário de maior transformação econômica.

Os investimentos públicos diretos vêm sendo alocados em um conjunto de obras públicas relacionadas à infraestrutura, particularmente na área de energia elétrica (geração e transmissão), logística e construção de estradas. Indiretamente, o Estado também vem atuando via empresas estatais e sistema estatal de financiamento. Do lado da iniciativa privada, em termos gerais, os investimentos passam pela logística, implantação de indústrias e expansão da área de atuação nos diferentes complexos que operam na Amazônia. Por exemplo, algumas iniciativas já em andamento e outras anunciadas têm especificidades que mudam de atividade para atividade.

No complexo mineral, os investimentos vão nessa direção (guseiras, aciarias, cimento e calcário); no complexo celulose (plantio de floresta, fábricas), na logística (duplicação de ferrovias, construção e ampliação de complexos portuários), no complexo da soja (compra de terras, ampliação de áreas, indústrias de beneficiamento). [...] As fontes de financiamentos são diversas, inclusive estatais (BNDES), mas também próprias, de bancos e fundos de investimentos. Vale, Petrobras, Suzano, Agropalma e Bung Cargill são algumas das grandes empresas presentes nesse cenário atual da Amazônia. (MESQUITA et al., 2015, p. 284).

Uma das principais características da produção agroflorestal é a imensa demanda por área plantada, para que seja contínua e intensa a rotação de cultura no período de sete anos necessários para que o eucalipto esteja pronto para servir de matéria-prima. Por isso, houve um rápido aumento de áreas já plantadas e de terras prontas para o plantio, além de arrendamentos. Houve uma tipificação a partir do eucalipto em todo o Maranhão, com destaque para sua porção amazônica, como é possível observar no gráfico abaixo (Figura 4).

Figura 4 - Maranhão: Evolução de áreas destinadas ao plantio de eucalipto em hectares.

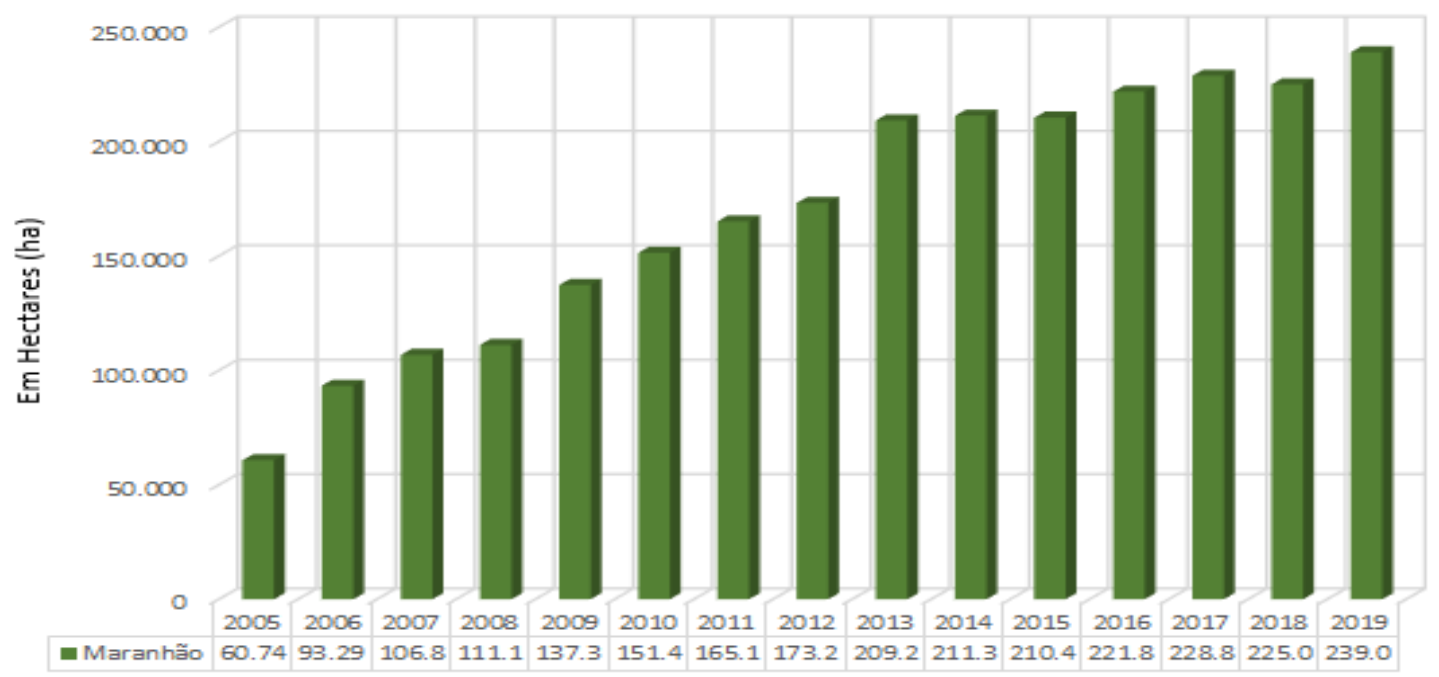

Fonte - Indústria Brasileira de Árvores (IBA), 2020. Org. Os autores, 2020.

Embora se acredite que os dados reais sejam superiores aos oficiais, é expressivo o aumento no quantitativo de áreas plantadas em um período de 15 anos, como apresentado no gráfico acima (Figura 4). Em 2005 a base plantada resultante da CELMAR e da cadeia siderúrgica estadual era de

$\begin{array}{lllll}\text { Caminhos de Geografia } \quad \text { Uberlândia-MG } & \text { v. 22, n. 79 } & \text { Fev/2021 } & \text { p. 219-231 Página } 227\end{array}$


60.74 mil hectares que aumentam para 111.120 mil hectares em 2008 (ano do início das obras de construção fabril) chegando a 239.078 mil hectares plantados no ano de 2019 , aumento de $398 \%$ da área inicial no intervalo apresentado.

Observa-se na Figura 5, abaixo, a concentração de áreas destinadas à monocultura do eucalipto principalmente em torno da fábrica da Suzano, na região de divisa entre os estados do Maranhão e Pará, na área de influência do Projeto Grande Carajás. O avanço da atual fronteira agrícola do eucalipto segue em direção a assentamentos rurais, pequenos grupos agricultores, além de terras indígenas, o que tem resultado em conflitos socioambientais das mais diversas ordens, principalmente aqueles pelo uso do território.

Figura 5 - Áreas de plantação de eucalipto em área amazônica.
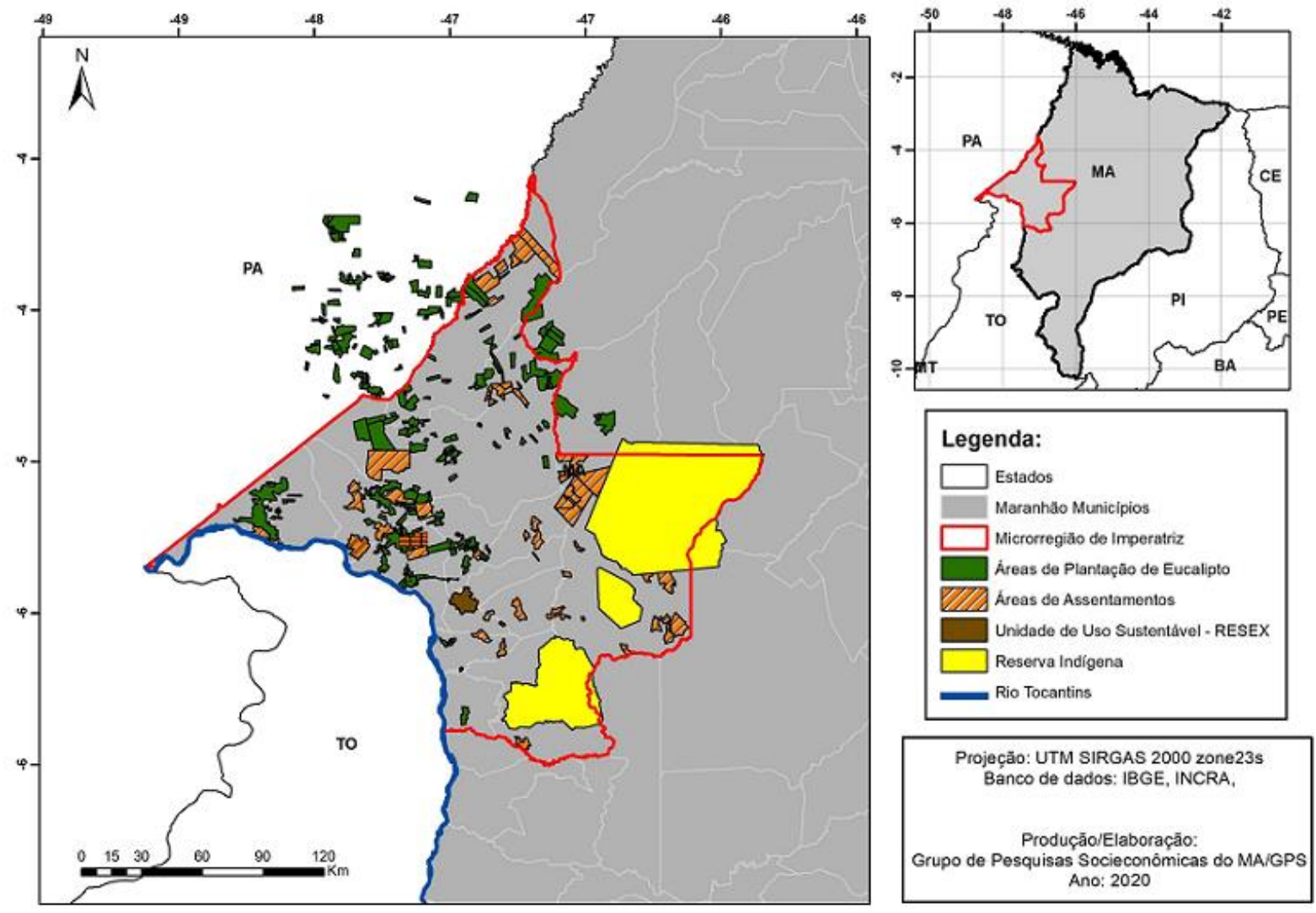

Organização: Os autores (2020).

Esses conflitos decorrem de todo o processo histórico da fronteira agrícola do eucalipto na Amazônia Legal, no qual figuram: implantação e funcionamento de grandes projetos, como os complexos de produção de ferro-gusa, em Açailândia; compra de terras pelo projeto CELMAR; e produção de lingotes de alumínio pela ALUMAR, em São Luís.

A maior parte das fazendas de eucalipto (Figura 6) estão localizadas na região de fronteira entre Maranhão (em especial a microrregião de Imperatriz), Pará e Tocantins. A movimentação de matériaprima ocorre, portanto, em um fluxo interestadual, pois parte das áreas do Pará também foram incorporadas à produção. Em todas essas regiões, a presença da monocultura modificou intensamente a paisagem natural. Invadindo assim os limites de áreas historicamente frágeis, como assentamentos, unidades de conservação, reservas indígenas, etc.

Embora não seja um processo homogêneo, a intensificação da silvicultura do eucalipto no Maranhão reforça um padrão histórico de reprodução do capital, baseado na produção de commodities ou de produtos de baixo valor agregado, um padrão bastante predominante em regiões periféricas. Isso gera aumento da concentração de terras e transformações na agricultura tradicional na região. 
Figura 6 - Fazendas de cultivo de eucalipto na microrregião de Imperatriz - MA.

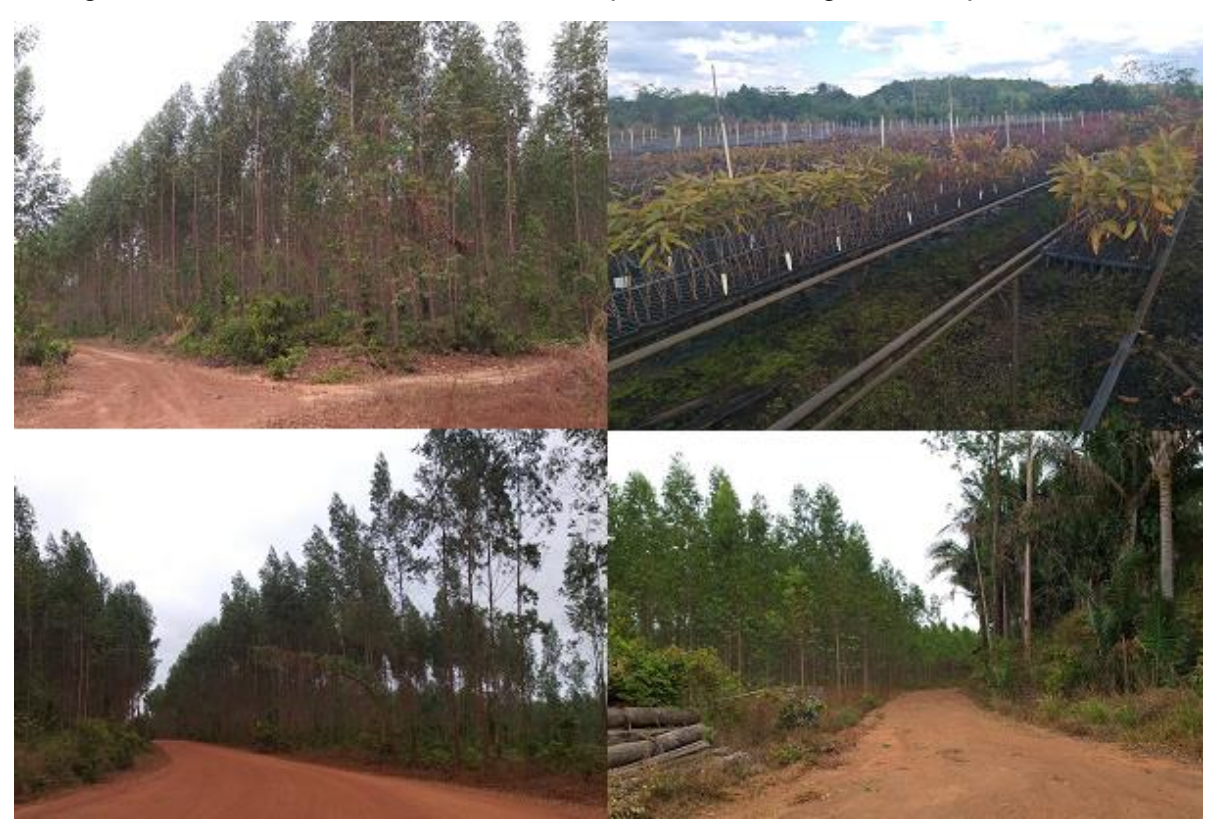

Fonte - Os autores (2020).

Esse padrão firma-se em especializações produtivas que transformam os territórios a partir de lógicas econômicas hegemônicas. No caso do Maranhão, os territórios passam a produzir para o mercado externo; atividades tradicionais e características do estado, como o extrativismo, a agricultura e a pecuária de subsistência perdem força frente à produção de commodities. No atual cenário, é a pasta de celulose que cresce à frente de outras mercadorias de relevância histórica.

Quando consideramos os cinco principais produtos exportados pelo Maranhão (Figura 7), no período compreendido entre 2001 e 2018, nota-se que todos eles são commodities de ordem agrícola ou mineral, o que nos remete à consolidação de um modelo de especialização voltada principalmente para a pilhagem de recursos naturais.

Figura 7 - Maranhão: Cinco principais commodities exportadas em toneladas (2001-2018).

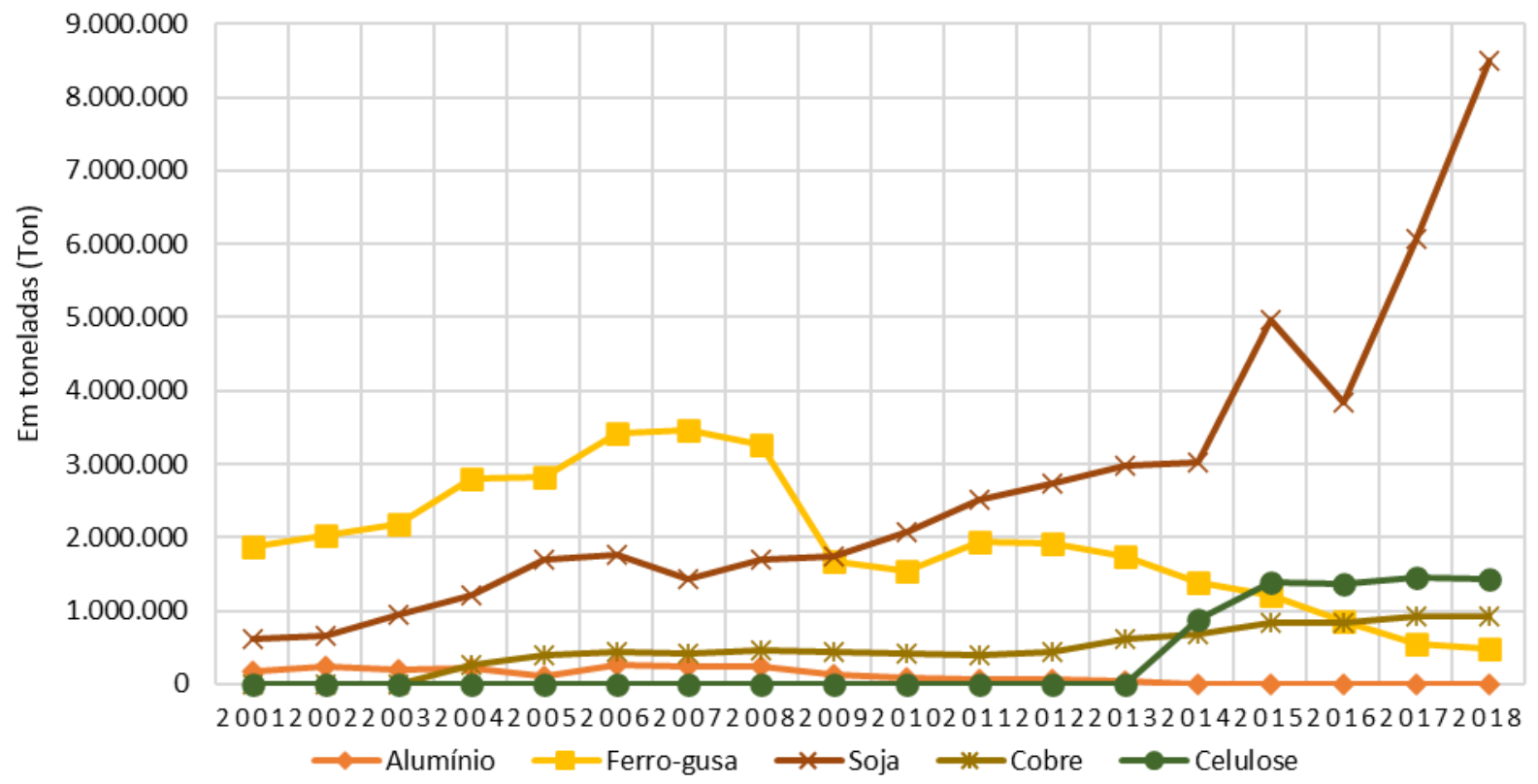

Fonte - EMAP (2020). Organização: Os autores, 2020. 
A partir de 2015, devido aos altos custos de operação, o Consórcio Alumar/Alcoa encerrou a produção de lingotes de alumínio na capital do estado, o que pode ser notado pela baixa na produção apresentada no gráfico. De modo semelhante, houve expressiva redução da produção de ferro-gusa nos últimos anos. Das três commodities minerais, apenas o cobre foi mais produzido a partir de 2012.

Por outro lado, nos últimos anos, as commodities de ordem agrícola têm assumido expressividade no estado, conforme se pode observar pelo volume de toneladas produzidas apresentado na Figura 7, o que é fruto do contexto exposto neste trabalho. A pasta de celulose, que só passou a ser produzida em 2013 e exportada em 2014, cresceu de tal forma que perde apenas para a soja, principal atividade resultante da fronteira agrícola intensificada no sul do estado.

As informações contidas no gráfico 7 , sugerem processo de reestruturação produtiva do Maranhão a partir da concentração das principais commodities exportadas. Se no passado havia uma predominância naquelas oriundas da mineração, estas - mesmo com a forte presença e relevância da Vale na região - começam a dividir lugar com novo e mais denso estágio de expansão da fronteira agrícola, e como tal, avanço do agronegócio produtor de soja e eucalipto.

\section{CONSIDERAÇÕES FINAIS}

Ao contrário de outros movimentos brasileiros de fronteira agrícola, como os movimentos sulistas pela ampliação de terras para a plantação da soja, a inserção do eucalipto na Amazônia maranhense, bem como no restante do estado do Maranhão, não foi resultado de um movimento próprio que tivesse a plantação de eucalipto como um objetivo e um fim. Ou seja, a silvicultura do eucalipto emerge como subproduto não intencional, pelo menos inicialmente, de movimentos macroeconômicos iniciados no fim da década de 1970 e concluídos no início da de 1980, que resultaram em grandes projetos na região. Foi somente com a consolidação do empreendimento Carajás, de propriedade da então CVRD, profundamente conectado com as infraestruturas de transporte (em especial a Estrada de Ferro Carajás) e os complexos industriais produtores de ferro-gusa e alumínio na cidade de Açailândia, que o plantio de eucalipto em larga escala passou a ter papel essencial na produção de energia no Maranhão.

A base florestal iniciada pela CVRD estendeu-se, na década de 1990, na região de fronteira entre o Maranhão e o Pará, permitindo o início dos primeiros investimentos para a produção de commodities agroflorestais, no caso, a CELMAR. Ela foi responsável não apenas pela intensificação na especulação, compra e concentração de terras até metade dos anos 2000, mas também, pela inserção de outro estágio da fronteira agrícola agroflorestal no estado.

A chegada da Suzano Papel e Celulose no Maranhão em 2008, beneficiando-se de mais de três décadas de movimentos de fronteira, reestrutura os movimentos do passado e consolida conjuntamente com sua base plantada novo estágio da fronteira agrícola no Maranhão, mas agora, com o eucalipto como cultura motriz do processo, e não apenas subproduto de empreendimentos maiores. E como tal, a produção de commodities agroflorestais, ganha novo estágio na região.

\section{AGRADECIMENTOS}

Este trabalho é resultado de pesquisa desenvolvida com auxílio financeiro concedido pela Fundação de Amparo à Pesquisa e ao Desenvolvimento Científico e Tecnológico do Maranhão (FAPEMA) sob a coordenação do Grupo de Pesquisas Socioeconômicas do MA - GPS/UEMASUL.

\section{REFERÊNCIAS}

ANTONANGELO, A.; BACHA, C. J. C. As fases da silvicultura no Brasil. Revista Brasileira de Economia, Rio de Janeiro, v. 52, n. 1, p. 207-238, jan./mar. 1998.

BRASIL. Lei no 5.173, de 27 de outubro de 1966. Dispõe sobre o Plano de Valorização Econômica da Amazônia; extingue a Superintendência do Plano de Valorização Econômica da Amazônia (SPVEA), cria a Superintendência do Desenvolvimento da Amazônia (SUDAM), e dá outras providências. Brasília, DF: Presidência da República, 1966. Disponível em: http://www.planalto.gov.br/ccivil_03/leis/15173.htm. Acesso em: 7 out. 2020.

BECKER, B. K. Amazônia: geopolítica na virada do III milênio. Rio de Janeiro: Garamond, 2007.

$\begin{array}{llll}\text { Caminhos de Geografia } \quad \text { Uberlândia-MG } & \text { v. 22, n. 79 } & \text { Fev/2021 } & \text { p. 219-231 Página } 230\end{array}$


Geopolítica da Amazônia. Estudos Avançados, São Paulo, v. 19, n. 53, p. 71-86, abr. 2005.

. Os eixos de integração e desenvolvimento e a Amazônia. Revista Território, Rio de Janeiro, v. 4, n. 6, p. 29-42, jan./jun. 1999. https://doi.org/10.1590/S0103-40142005000100005 1985. . Fronteira e urbanização repensadas. R. Bras. Geogr. Rio de Janeiro, v. 36, n. 2, p. 357-371,

COELHO, T. P. Projeto Grande Carajás: trinta anos de desenvolvimento frustrado. Marabá: Editorial iGuana, 2015. (Coleção A questão mineral no Brasil, v. 1).

DNIT - Departamento Nacional de Infraestrutura de Transportes. Infraestrutura rodoviária do Brasil. Brasília: DNIT, 2016. Disponível em: https://www.gov.br/dnit/pt-br/assuntos/infraestrutura-rodoviaria. Acesso em: 7 out. 2020.

EMAP - Empresa Maranhense de Administração Portuária. Relatório de movimentação de cargas portuárias no Maranhão. [São Luís]: EMAP, 2020. Disponível em: http://www.emap.ma.gov.br/portodo-itaqui/operacoes-portuarias/movimentacao-de-carga. Acesso em: 10 abr. 2020.

IBA - Indústria Brasileira de Árvores. Relatório de produção da silvicultura no Brasil. Brasília: IBÁ, 2020. Disponível em: https://www.iba.org/. Acesso em: 10 fev. 2020.

IBGE - Instituto Brasileiro de Geografia e Estatística. Produção extrativista e da silvicultura no Brasil. Rio de Janeiro: IBGE, 2019. Disponível em: https://www.ibge.gov.br/. Acesso em: 14 fev. 2020.

. Infraestrutura de transporte e logística no Brasil. Rio de Janeiro: IBGE, 2010. Disponível em: https://mapas.ibge.gov.br/tematicos/infra-estrutura-e-logistica. Acesso em: 14 fev. 2020.

INCRA - Instituto Nacional de Colonização e Reforma Agrária. Cadastro Nacional de Imóveis Rurais - CNIR. Brasília: INCRA, 2020. Disponível em: http://www.incra.gov.br/pt/cnir.html. Acesso em: 7 out. 2020.

MATIAS, M. A implantação da indústria de celulose no Maranhão: Celmar na Região Tocantina. Belém: Seminário Consulta Carajás, 1994. (Cartilha n. 3)

MESQUITA, B. A. et al. Formação socioeconômica do estado do Maranhão. In: CASTRO, E. R.; CAMPOS, I. (org.) Formação socioeconômica da Amazônia. Belém: NAEA/UFPA, 2015. p. 225319.

MMA - Ministério do Meio Ambiente. Zoneamento Territorial da Amazônia Legal brasileira. Brasília: MMA, 2020. Disponível em: https://www.mma.gov.br/informma/item/7526-zoneamentoterritorial.html. Acesso em: 7 out. 2020.

MONTEIRO, M. A. Siderurgia na Amazônia Oriental brasileira e a pressão sobre a floresta primária. In: ENCONTRO NACIONAL DA ANPPAS, 2. 2004, Indaiatuba. Anais [...]. Indaiatuba: Associação Nacional de Pós-Graduação e Pesquisa em Ambiente e Sociedade, 2004.

OLIVEIRA, A. B. Indústria de celulose e o avanço da silvicultura do eucalipto na fronteira agrícola da Amazônia maranhense. Geosul, Florianópolis, v. 34, n. 71, p. 301-327, abr. 2019. Dossiê Agronegócios no Brasil. https://doi.org/10.5007/1982-5153.2019v34n71p301

SICSÚ, A. B.; LIMA, J. P. R. Fronteiras agrícolas no Brasil: a lógica de sua ocupação recente. Nova Economia, Belo Horizonte v. 10, n. 1, p. 109-138, jul. 2000.

SUZIGAN, W. Indústria brasileira: origem e desenvolvimento. São Paulo: Hucitec; Campinas: Editora da Unicamp, 2000.

VIANA, M. B. O eucalipto e os efeitos ambientais do seu plantio em escala. Brasília: Consultoria Legislativa da Câmara dos Deputados, 2004.

Recebido em: 24/04/2020

Aceito para publicação em: 09/10/2020 